\title{
The COVID-19 Pandemic Through the Lens of a Medical Student in India
}

\author{
Surobhi Chatterjee.
}

\section{The Experience}

The pandemic has brought an unprecedented challenge before the global community. It can be labeled as one of the most severe pandemic which has already affected 210 countries including India. One of the communities hardest hit is the student body. Much akin like every other medical student, I was extremely anxious. I am an Indian. I am from Lucknow, Uttar Pradesh, one of the most densely populated areas in the world. When just put in plainly, this is not a lot to concern about but once you understand the vulnerability of the population in my country and the immediate restriction measures the government had to take to restrict infection, being anxious, just comes naturally. Being a medical student who had just arrived home after the endsemester exams; the closing of universities, schools, public places, any forms of social interaction beginning from $13^{\text {th }}$ March, ${ }^{2}$ was just the silence before the storm. Since March $24^{\text {th }}$, the entire nation of a 1.3 billion people is in complete lockdown. ${ }^{3}$ Most universities had to cancel their examinations, the Undergraduate national examinations for premier medical and engineering institutes, the board examinations of senior secondary and high school and internal school exams were postponed indefinitely. The lockdown was implemented for 21 days which had to be extended till $3^{\text {rd }}$ of May taking into account the increasing number of cases and the impact of social distancing in fighting the pandemic.

\section{How did universities and schools respond?}

With the government's advisory on immediate closing of institutions, the student and education bodies both were faced with the challenge of provision of quality education via online platforms. ${ }^{2}$ Most universities started live-online classes. Schools even started their own e-learning platforms for students. Everybody had their reservation regarding this complete shift from lecture discussions to an online portal altogether. In a low- and middle-income country (LMIC) like India, the internet connectivity and global access to it is still not a universal privilege. Learning of these new skills by the senior faculty members was though difficult and time-intensive, but it has yielded a significant impact in decreasing the psychosocial trauma and anxiety the student community faced.

\section{Medical schools and their transformation}

Medical schools are known for their intense curriculum and workload. They have adhered to their traditional in-house lectures and bedside teaching since a long time. The pandemic brought a diabolic change in this rigorous teaching schedule. Doctors and healthcare workers being the backbone of the community's fight against pandemic are already in testing times. It was difficult at first for medical schools to adapt but with the passage of time and dawn of realization, they were quick to resort.
My experience with online teaching has not been a smooth sail either, though it is important to understand a few points here. There is poor internet connectivity in some areas, (mine thankfully being an exception) which is partly even due to heavy traffic. Complaints ranging from the access, audio and video quality to sometimes even about the background noises were raised regarding the live streamed classes, which was faced by me too, though rarely. The online streaming of lectures by senior faculty wearing masks and some in their full gear kept making me realize the precipitous amount of workload the medical community is drenched with. Here, it is even important to understand that my institute, King George's Medical University and associated hospitals, a premier tertiary-care medical school of India, is also combating the immense workload of regularly screening and treating a large number of COVID-19 suspects from around the state and, like, many other medical institutes, is also trying its level best to provide quality education to students. There are several factors that acts as barriers for online education, with a) academic skills, b) technical skills, c) cost and internet access, d) time and motivation for studies and e) technical issues, being some of them. ${ }^{4}$

In brief, India, which is at the face of this unprecedented crisis, since the Spanish Flu, the turmoil both economically and mentally, has been immense. The world's $2^{\text {nd }}$ most populous country has been under complete lockdown since $25^{\text {th }}$ March. Universities though have responded by providing e-learning platforms for its students, a lot still needs to be done especially for the medical students, who are next in line for this fight. Student-centered approach needs to be implemented including doubt clearing sessions via online portals, virtual bedsidestimulation software, creative conceptualization and student engagement, keeping in mind the 4 key pillars- skills, resources, institutional strategies and support and attitude. ${ }^{5}$ The interdepartmental co-ordination needs to be ensured as well. ${ }^{6}$ India, with its stringent lockdown measures is an example for most low- and middle-income and even affluent countries and was applauded by WHO' and by the Oxford COVID-19 Government Response Tracker (OxCGRT) for the same. ${ }^{8}$ Hence, India can revolutionize the field of costeffective online education for others to learn from.

\section{MBBS Student, King George’s Medical University, Lucknow, India.}

About the Author: Surobhi Chatterjee is currently a final year undergraduate student of King George's Medical University, Lucknow, India. She is also the second runner up of the Undergraduate Quiz organized by National Conference of International Association of Social Psychiatry and has published 2 review articles in the Indian journal of Health, Sexuality and Culture. She has received distinction in microbiology, ophthalmology and public health and has recently got a rank of 5 among the 250 students of her batch. 


\section{Experience}

\section{References}

1. Worldometers. Countries-where-coronavirus-has-spread. 2020. Cited Apr 26, 2020; Available from: https://www.worldometers.info/coronavirus/countrieswhere-coronavirus-has-spread/.

2. PTI. All UP schools and colleges will remain closed till March 22. The Times 0 India. 2020. Cited Apr 13, 2020. Available from: https://timesofindia.indiatimes.com/home/education/news/all-up-schools-andcolleges-will-remain-closed-till-march-22-in-wake-of-coronavirus-outbreakadityanath/articleshow/74609844.cms.

3. BBC. Coronavirus: India enters 'total lockdown' after spike in cases. BBC World Asia. 2020. Cited Mar 25, 2020. Available from: https://www.bbc.com/news/world-asia-india-52024239.

4. Muilenburg LY, Berge ZL. Student barriers to online learning: A factor analytic study. Distance Education. 2005; 26(1): 29-48.
5. O'Doherty D, Dromey M, Lougheed J, Hannigan A, Last J, McGrath D. Barriers and solutions to online learning in medical education - an integrative review. BMC Med Educ. 2018 Jun 7;18(1):130.

6. Walsh K. Online assessment in medical education-current trends and future directions. Malawi Med J. 2015 Jun;27(2):71-2.

7. Singh Y. COVID-19: UN, WHO praise India for its lockdown. Rediff News. 2020. Cited Mar 25, 2020. Available from: https://www.rediff.com/news/report/unwho-praise-india-for-its-lockdown-coronavirus/20200325.htm.

8. CNBCTV18. Study reveals India's response to coronavirus most stringent. CNBCTV18. India: CNBCTV; 2020. Available from: https://www.cnbctv18.com/healthcare/study-reveals-indias-response-tocoronavirus-most-stringent-5666531.htm.

\section{Acknowledgments}

None.

Conflict of Interest Statement at Funding

The Authors have no funding, financial relationships or conflicts of interest to disclose.

Author Contributions

Conceptualization, methodology, writing-original draft, preparation, writing,-review and editing, and visualization: Surobhi Chatterjee

Cite as:

Chatterjee S. The COVID-19 Pandemic Through the Lens of a Medical Student in India. Int J Med Students. 2020 Jan-Apr;8(1):82-83.

This work is licensed under a Creative Commons Attribution 4.0 International License

ISSN 2076-6327

This journal is published by the University Library System, University of Pittsburgh as part of the Digital Publishing Program and is co-sponsored by the University of Pittsburgh Press. 